\title{
Cyclical helping hands: seasonal tailwinds differentially affect migrating Oriental Storks (Ciconia boyciana) travel speed
}

Shujuan Fan' ${ }^{1}$, Qingshan Zhao ${ }^{2}$, Hongbin Li ${ }^{2,3}$, Baoguang Zhu' ${ }^{4}$, Shubin Dong ${ }^{4}$, Yanbo Xie ${ }^{5}$, Lei Cao ${ }^{1,2,3^{*}}$ (1) and Anthony David Fox ${ }^{6}$

\begin{abstract}
Background: The Oriental Stork (Ciconia boyciana) breeds in southeastern Siberia and parts of northeast China, and winters mainly in southeast China. Although the autumn migration pattern of Oriental Storks has been previously described, differences between spring and autumn migration travel speed in relation to wind assistance were unknown.

Methods: Using GPS/GSM transmitters, we tracked the full migrations of 18 Oriental Storks during 2015-2018 to compare differences in autumn and spring migration patterns, and combined the satellite telemetry data with the National Center for Environmental Prediction Reanalysis data to explain the relationship between 850 mbar wind vectors and seasonal differences in travel speed.

Results: Differences in tailwinds contributed to significant differences in daily average Oriental Storks travel speed in spring $(258.11 \pm 64.8 \mathrm{~km} /$ day) compared to autumn $(172.23 \pm 49.7 \mathrm{~km} /$ day, $p<0.001)$. Storks stopped significantly more often in autumn than spring (1.78 \pm 1.1 versus $1.06 \pm 0.9, p<0.05)$, but stopover duration $(15.52 \pm 12.4$ versus $16.30 \pm 15.1$ days, respectively, $p=0.3$ ) did not differ significantly. Tailwinds at $850 \mathrm{mbar}$ pressure level (extracted from the National Center of Environmental Prediction Reanalysis data archive) significantly affected daily flying speed during spring and autumn migration. Tailwind conditions in spring (mean $4.40 \pm 5.6 \mathrm{~m} / \mathrm{s}$ ) were always more favourable than in autumn when they received no net benefit $(0.48 \pm 5.6 \mathrm{~m} / \mathrm{s}, p<0.001)$. Despite mean spring migration duration being less than autumn ( $27.52 \pm 15.9$ versus $32.77 \pm 13.4$ days, $p=0.17)$, large individual variation meant that this duration did not differ significantly from each other.
\end{abstract}

Conclusions: For long distance migratory soaring birds (such as storks), relative duration of spring and autumn migration likely relates to the interaction between imperative for earliest arrival to breeding grounds and seasonal meteorological conditions experienced en route.

Keywords: Ciconia boyciana, GPS/GSM tracking, Migration, Tailwind, Travel duration, Travel speed

\footnotetext{
*Correspondence: leicao@rcees.ac.cn

${ }^{2}$ State Key Laboratory of Urban and Regional Ecology, Research

Center for Eco-Environmental Sciences, Chinese Academy of Sciences, Beijing 100085, China

Full list of author information is available at the end of the article
}

\section{Background}

That weather conditions affect the timing and flight behaviour of long-distance bird migration is well known (Shamoun-Baranes et al. 2017; Becciu et al. 2019). For instance, the migration of large terrestrial soaring birds may be affected by local atmospheric conditions, as it is known that they prefer to use thermals to gain altitude before they glide towards their destination (Norberg

(c) The Author(s) 2020. This article is licensed under a Creative Commons Attribution 4.0 International License, which permits use, sharing, adaptation, distribution and reproduction in any medium or format, as long as you give appropriate credit to the original author(s) and the source, provide a link to the Creative Commons licence, and indicate if changes were made. The images or other third party material in this article are included in the article's Creative Commons licence, unless indicated otherwise in a credit line to the material. If material is not included in the article's Creative Commons licence and your intended use is not permitted by statutory regulation or exceeds the permitted use, you will need to obtain permission directly from the copyright holder. To view a copy of this licence, visit http://creativeco mmons.org/licenses/by/4.0/. The Creative Commons Public Domain Dedication waiver (http://creativecommons.org/publicdomain/ zero/1.0/) applies to the data made available in this article, unless otherwise stated in a credit line to the data. 
2012). However, of all atmospheric conditions, wind has perhaps the greatest effect on migration of birds (Liechti 2006; Mellone et al. 2012; Safi et al. 2013; Rotics et al. 2016; Vidal-Mateo et al. 2016). For example, Becciu et al. (2018) found that soaring birds exploit tailwinds to move faster, confirmed by Shamoun-Baranes et al. (2003) who showed the migration ground speeds of White Storks (Ciconia ciconia) increased with tailwinds in both spring and autumn, but that this decreased in headwinds. Moreover, migration intensity also increases in tailwind conditions (Erni et al. 2002; Fox et al. 2003; Becciu et al. 2019), even within seasons at the same site in response to different wind directions (e.g. Desholm et al. 2014).

Several studies have attempted to analyse relationships between weather factors at fixed locations (such as meteorological stations) and the migration of large soaring birds. Although not all studies have revealed an impact of wind on migration (for example, wind had no effect on Osprey Pandion haliaetus migration; Thorup et al. 2006), many studies show selection for prevailing winds by large birds on, or about to undertake migration (Allen et al. 1996; Spaar and Bruderer 1996; Meyer et al. 2000).

As large, heavy soaring birds, storks are known to exploit tailwinds to aid their long distant movement (Becciu et al. 2018). Although the linkages between wind and migration are well studied for some species (Shamoun-Baranes et al. 2003; Vansteelant et al. 2015; Rus et al. 2017), no study has compared contrasting seasonal wind assistance on spring versus autumn migration of Oriental Storks (Ciconia boyciana), which is listed as an IUCN Endangered species (IUCN 2018). Despite a rich literature relating to the relative speed of spring versus autumn migrations (e.g. Alerstam and Hedenstrom 1998; Nilsson et al. 2013), there remain relatively few studies of the relative contributions of seasonal wind assistance to the speed and duration (i.e. the time taken to migrate between the breeding and wintering grounds) of spring and autumn migrations (e.g. Koelzsch et al. 2016). To address the knowledge gap for the Oriental Stork we therefore here present a study comparing the differential effects of wind parameters on a soaring bird during spring and autumn migration episodes.

The Oriental Stork has an estimated population of $c$. 3000 individuals and breeds along the Russia-China border, primarily in the Heilongjiang and Ussuri River basins and winters mainly in the middle and lower Yangtze River Floodplain in China (Wang and Yang 1995; Barter et al. 2004). Shimazaki et al. (2004) were the first to describe autumn migration timing and routes, breeding, staging and wintering areas of Oriental Storks based on 13 birds tracked using satellite telemetry during period 1998-2000. We here combine our own telemetry data from 18 instrumented Oriental Storks with modelled multi-year macro-scale wind patterns to understand seasonal differences in migration strategies of the Oriental Stork by comparing the differences in spring and autumn migration, and try to explain the observed seasonal differences in travel speed due to differential tailwinds.

\section{Methods}

\section{Animal capture and GPS tracking}

We caught 18 juvenile Oriental Storks in Honghe National Nature Reserve $\left(47^{\circ} 47^{\prime} \mathrm{N}, 133^{\circ} 40^{\prime} \mathrm{E}\right)$, Heilongjiang Province, China, during 2015 to 2018 (for full details see Additional file 1: Table S1) and equipped them with waterproof solar-charged battery-powered backpack mounted GPS transmitters. Devices recorded their latitude and longitude every 60-180 min (horizontal accuracy $9.6 \pm 5.6 \mathrm{~m} \mathrm{SE}$ in field tests, see Additional file 2: Supplementary Methods for full details) with date and time stamp, transmitted from the on-board memory every 8 to $24 \mathrm{~h}$ through the mobile phone network, for retrieval and analysis. All birds completed one autumn migration and the subsequent spring migration back to the summering areas, which form the basis for 36 individual migration episodes analysed here.

\section{Segmentation of movement bouts to identify migration/ stopover periods and sites}

We used the methods described in Wang et al. (2018) to segment movement tracks into "fly" and "non-fly", then we visualized the movement using Google Earth to pinpoint the arrival and departure time at each site. We define the cluster of non-fly durations of more than $48 \mathrm{~h}$ as a stopover (Koelzsch et al. 2016). Based on these movement segmentations, it is possible to establish arrival and departure time at breeding and wintering grounds, as well as stopover sites along the migration route. We calculated migration distance as the cumulative distance flown by each individual between the point of departure from breeding/wintering area to the point of arrival at wintering/breeding area, excluding local movements within the stopover sites. We estimated migration duration as the time taken between the point of departure from breeding/wintering area to the point of arrival at wintering/breeding area. We extracted the number of stopovers made by each individual and calculated the cumulative time spent at all of these during a single migration as stopover duration. Finally, we subtracted stopover duration from migration duration to obtain travel duration and divide migration distance by travel duration to derive travel speed.

Within each flight segment, distance travelled $(\mathrm{km})$ was calculated from one point estimate to the next as the great circle distance between data points. Because the time between successive reliable location estimates 
varied, we divided the distance between successive points by the time interval between them to calculate the flying speed at each point.

\section{Meteorological data and calculations}

In order to determine the degree of head and tail winds experienced by storks along their migratory journey, we generally followed the methods of Shamoun-Baranes et al. (2003). We used wind data at a pressure level of 850 mbar, obtained from the National Center of Environmental Prediction (NCEP) Reanalysis data archives. These data have the advantage of being modelled at high spatial and temporal resolution across the entire globe based on actual real time observations, so data values are divided into four quality classes, dependent upon the relative degree of influence from observations or the model (Kalnay et al. 1996). The 850 mbar U and V wind components (i.e. instantaneous wind speed along the latitudinal and longitudinal orientations, respectively) used here are the most reliable of the generated variables. Although data can be accessed over specified spatial and temporal scales, we interpolated these data to points in space and time to coincide with stork movements. Data were extracted using R package "RNCEP" (Kemp et al. 2012), which contains functions to retrieve, organize, and visualize weather data from the NCEP/NCAR Reanalysis and NCEP/DOE Reanalysis II datasets.

Examination of the cumulative diurnal distribution of instantaneous flying speeds showed that Oriental Storks travel exclusively during daylight and roost at night, moving almost exclusively between 09:00 and 18:00 local time and that flying speed peaked at 14:00 local time $(8 \mathrm{~h}$ ahead of UTC, see Additional file 1: Fig. S1). We confined our analysis to Oriental Storks flying at speeds greater than $4 \mathrm{~m} / \mathrm{s}$ (Bengtsson et al. 2014) between 09:00 and 18:00 local time. In order to reduce variance in speed in relation to time of the day, or when several hours passed between reliable GPS locations, we estimated average daily flying speed between 09:00 and 18:00 local time. Average daily flying speed was calculated as the mean of all flying speeds from 09:00 and 18:00 local time each day, this dependent variable we labelled "daily flying speed" $(\mathrm{km} / \mathrm{h})$, which we analysed in relation to wind aloft (850 mbar) (Shamoun-Baranes et al. 2003). Flight heading for a given day was calculated as the angle between the first and last point of each flying segment in relation to wind direction.

$\mathrm{U}$ and $\mathrm{V}$ wind variables that were closest geographically and temporally to each point were used to calculate tail/head wind components (wind direction that follow or oppose the flight direction) (Shamoun-Baranes et al. 2003). The flight direction is the vector direction from the first point to the last point of each day. Although 850 mbar data relates to wind direction and speed at 1500 $\mathrm{m}$ above sea level, there is a predictable power law relationship with speeds at lower levels (Şen et al. 2012), that is, wind speed generally increases by $0.1 \mathrm{~m} / \mathrm{s}$ per $100 \mathrm{~m}$ of altitude for the first $1000 \mathrm{~m}$ above ground level (Parent and Ilinca 2011). Hence, modelled 850 mbar wind strength and direction give a good indication of the strength and degree of tail/head wind support to storks at 350-960 m above ground level where they typically fly on migration and a very strong indication of the relative cost/benefits of these winds when comparing autumn with spring. Tailwinds were expressed as positive values, while negative values represent the headwind component. Crosswinds were those perpendicular to the migration heading, where positive values represent winds from the left and negative values represent crosswinds from the right of the migration heading.

\section{Statistical analyses}

To test for significant differences between autumn and spring migration in each of the migration parameters (except for arrival and departure dates), we used paired $t$-tests (for those meeting the assumptions of normality and homogeneity of variance) and Wilcoxon signed-rank tests for the remaining parameters. We also used independent $t$-tests for differences in tailwinds in autumn versus spring, and Wilcoxon signed-rank tests for differences in daily flying speed during tail and head winds. We used a generalized additive model (GAM) to test for a relationship between daily flying speed and wind, as well as to test whether the difference in tailwind (calculated by subtracting the tailwinds in autumn from the tailwinds in spring) could explain the difference in daily flying speed (using the same calculation as for winds) between spring and autumn migration. All modelling and statistical analysis were performed using $\mathrm{R}$ software ( $\mathrm{R}$ Development Core Team 2017).

\section{Results}

All 18 Oriental Storks marked on the breeding grounds wintered in the Yangtze River Floodplain and returned the following spring to summer in the Heilongjiang River basin (Figs. 1, 2). Most individuals left summering areas in late October, arrived at the wintering areas in late November, started spring migration in late March, and returned to summering areas in late April. Migration parameter statistics are summarized in Additional file 1: Table S2 and represented as box-plots in Fig. 3a-f; note that all the following summary statistics are presented as mean values $\pm \mathrm{SD}$. There was no significant difference between spring and autumn in migration distance (2634.61 $\pm 380.1 \mathrm{~km}$ versus $2637.90 \pm 340.9 \mathrm{~km}$; Fig. 3a), migration duration (27.52 \pm 15.9 days versus $32.77 \pm 13.4$ 


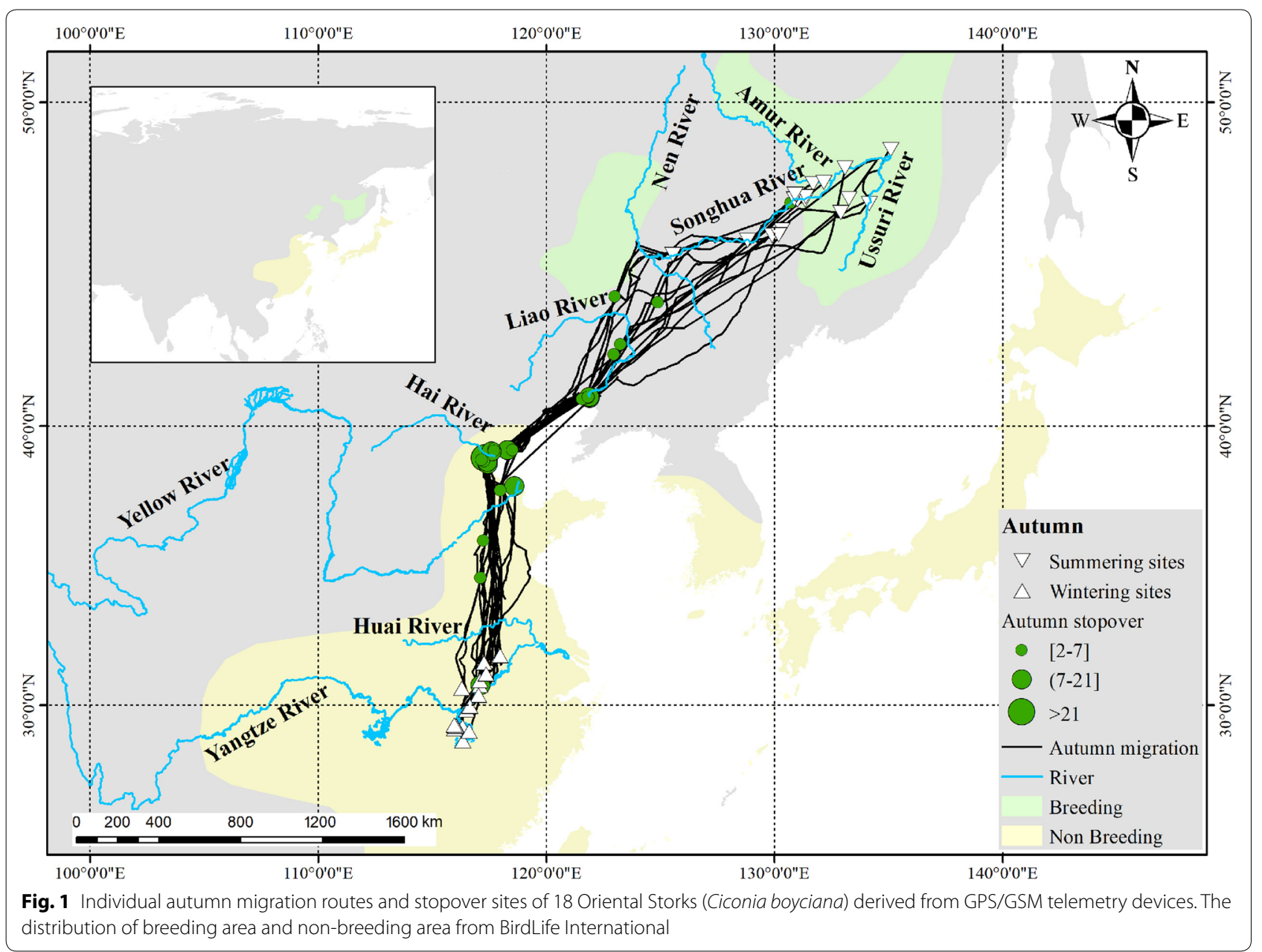

days; Fig. 3b) or stopover duration (16.30 \pm 15.1 days versus $15.52 \pm 12.4$ days; Fig. 3d). However, Oriental Storks travelled significantly faster in spring $(258.11 \pm 64.8 \mathrm{~km} /$ day versus $172.23 \pm 49.7 \mathrm{~km} /$ day; Fig. 3e), taking significantly less time travelling between wintering and breeding grounds than in autumn $(10.99 \pm 4.7$ days versus $16.85 \pm 7.9$ days; Fig. 3e-f). Number of stopovers differed significantly ( $1.06 \pm 0.9$ versus $1.78 \pm 1.1$; Fig. $3 \mathrm{c})$, but since most birds stopped once during either season, the difference is likely ecologically unimportant.

Daily flying speed was significantly related to tailwind at 850 mbar (GAM: df $=1.925, F=115.7, r^{2}=0.399$, $p<0.001$, Additional file 1: Fig. S2). The difference in seasonal tailwind was significantly related to the difference in seasonal daily flying speed (GAM: $\mathrm{df}=8.899, F=21$, $r^{2}=0.928, p<0.001$, Fig. 4). The difference in tailwind strength could explain the difference of daily flying speed between spring and autumn migration. There was a significant difference between daily flying speed during tailwinds $(34.28 \pm 10.3 \mathrm{~km} / \mathrm{h})$ versus headwinds $(22.74 \pm 5.0$ $\mathrm{km} / \mathrm{h}$, Wilcoxon signed-rank test: $p<0.001$, Fig. $3 \mathrm{~h}$ ).
There was also a significant difference between mean tailwind speed in spring $(4.40 \pm 5.6 \mathrm{~m} / \mathrm{s}$, significantly greater than zero, based on single sample $t$-test $p<0.001$ ) compared to autumn $(0.48 \pm 5.6 \mathrm{~m} / \mathrm{s}$, independent $t$-test: $p<0.001$, Fig. $3 g$, note that this latter value did not significantly differ from zero based on single sample $t$-test $p=0.15$ ).

\section{Discussion}

The benefits of migrating with tailwinds have been widely reported in other large bird species, such as Honey Buzzards (Pernis apivorus), White Storks and Ospreys (Shamoun-Baranes et al. 2003; Vansteelant et al. 2015; Rus et al. 2017). However, direct comparisons can be difficult, because for day migrating species that make use of thermals, day length greatly affects migratory duration and speed (Mellone et al. 2012). However, our study is the first to show that the speed of migration in the Oriental Stork is seasonally affected by differences in the benefit gained from tailwinds throughout the migration episodes, which predictably differed between spring and 


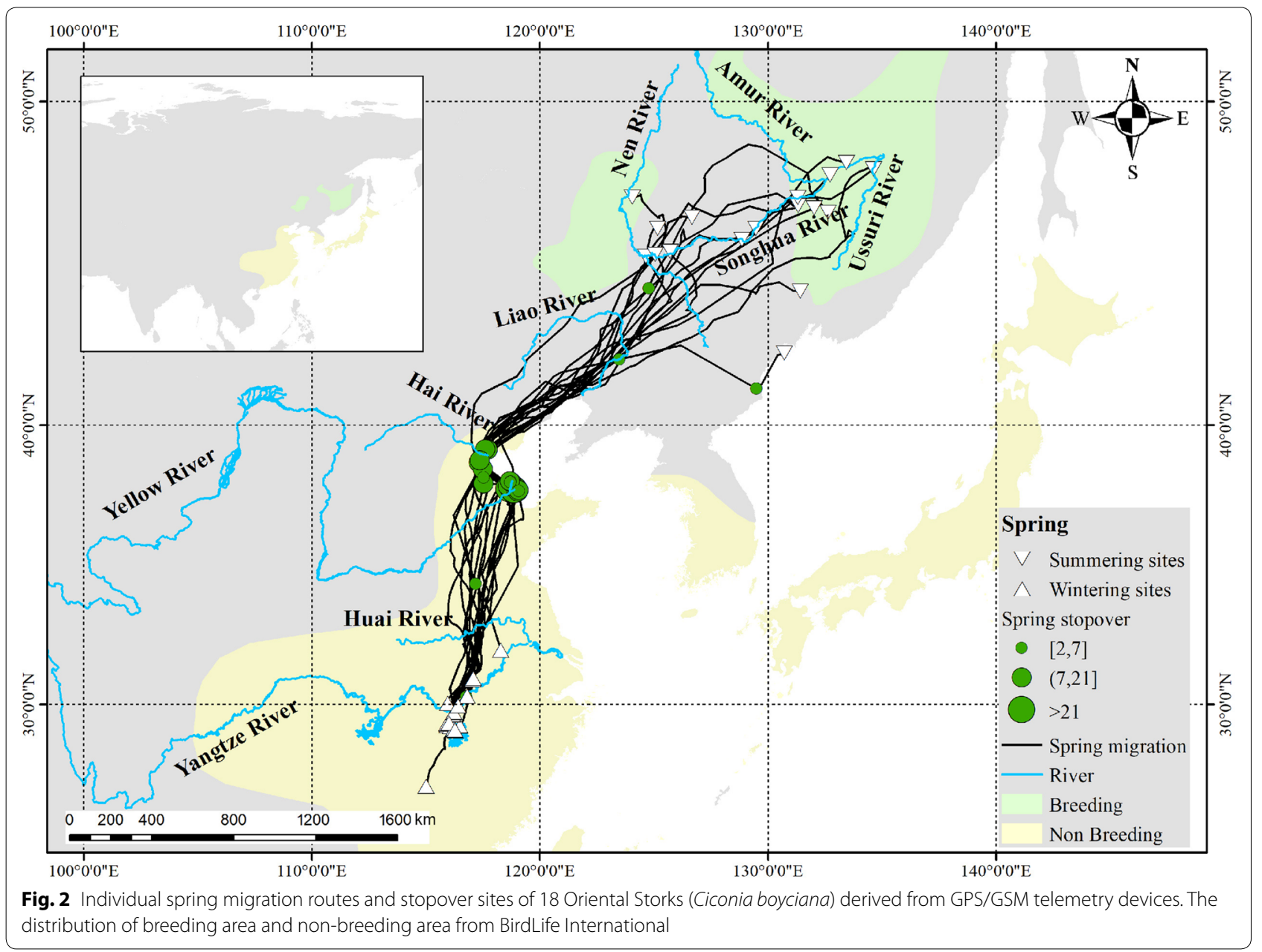

autumn. It is of course important to stress that our findings are from young Oriental Storks (which do not breed in their first year), and the behaviour of adults may be different from first year birds. In other species, age specific differences in migration schedules have been demonstrated, usually becoming more similar to adult migration patterns with age (Hake et al. 2003; Mueller et al. 2013; Sergio et al. 2014). Generally, in large-bodied birds, males arrive earlier than females, which may reflect their need to secure a breeding territory (Rotics et al. 2018), but in our study we could not distinguish between the sexes and territorial defence was not relevant.

We found tailwind assistance explained seasonal differences in daily Oriental Storks flying speed. The tailwind strength $(850 \mathrm{mbar})$ had a significant effect on daily flying speed both in spring and autumn migration, but because tailwinds were on average stronger in spring $(4.40 \pm 5.6 \mathrm{~m} / \mathrm{s})$ than in autumn $(0.48 \pm 5.6 \mathrm{~m} / \mathrm{s}$ when storks effectively gained no net benefit from tailwinds throughout migration), spring daily travel speed was faster than in autumn. Liechti et al. (1996) found that the average ground speed of White Storks migration in southern Israel was higher in autumn than in spring, due to a difference in prevailing tailwinds. Shamoun-Baranes et al. (2003) also found that tailwind had a significant impact on the average migration speed of White Storks in both spring and autumn, but in their study, autumn migration duration was shorter (26.1 \pm 4.9 days) than spring (49.1 \pm 15.0 days) compared to $32.77 \pm 13.4$ days and $27.52 \pm 15.9$ days respectively for Oriental Storks. Because of the large variation in migration duration between different individuals, this 5-day difference failed to attain statistical significance. Shamoun-Baranes et al. (2003) also speculated that wind assistance may explain part of the seasonal difference in mean migration speed in their European study of White Storks, where prevailing winds in spring were generally less advantageous than in autumn throughout their flyway.

Numerous studies of soaring birds have shown relationships between strength of tailwinds and speed of migratory birds. For example, peak movements or departures of migrants are associated with periods of favourable 

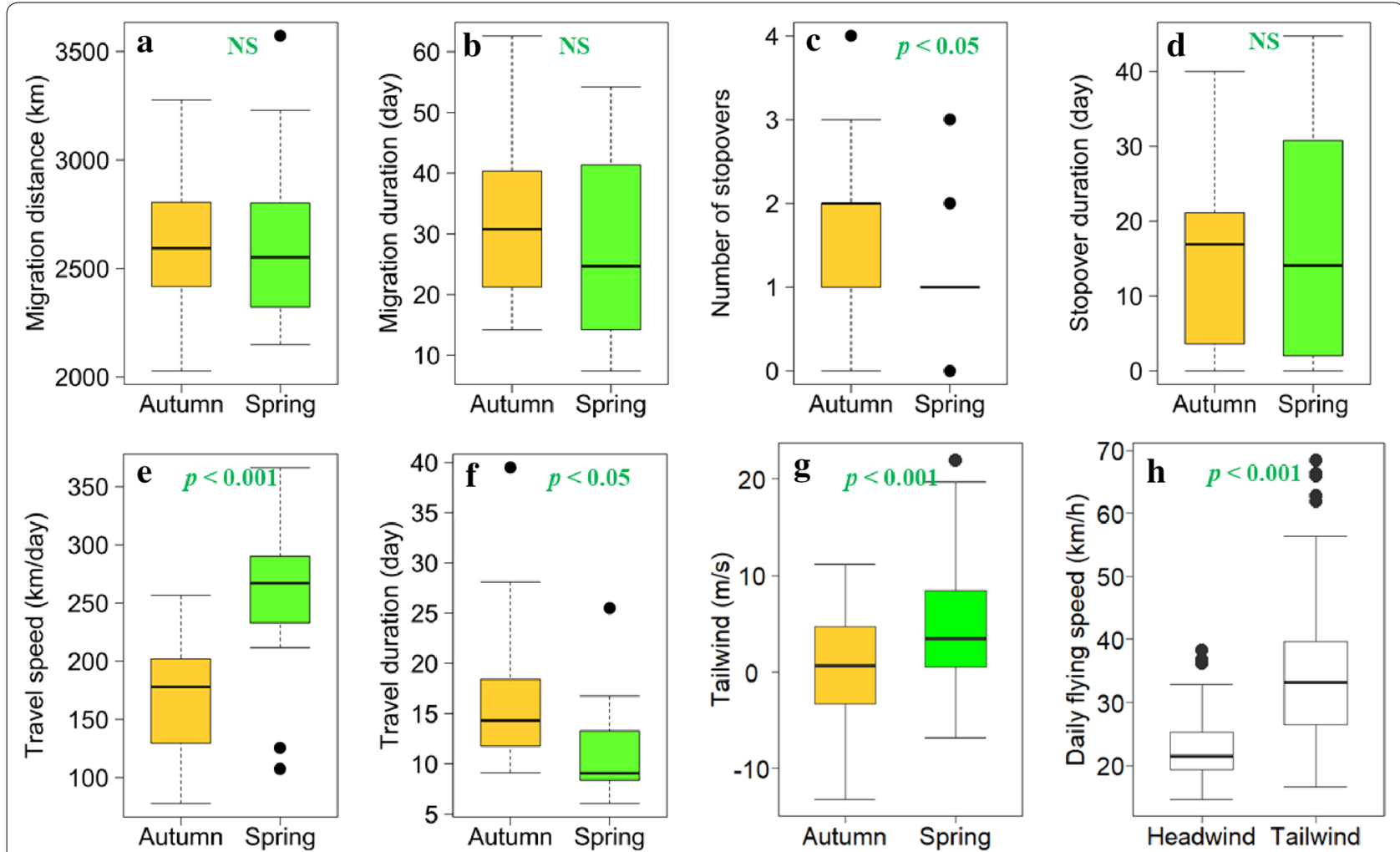

Fig. 3 Box plots (showing median, lower and upper quartiles, whiskers extend 1.5 times the interquartile range from the 25th and 75th percentiles and outliers) illustrating the differences between spring (green) and autumn (orange) migration parameters of tagged Oriental Storks (Ciconia boyciana) during migration. Individual graph plots show: a migration distance $(\mathrm{km})$, b migration duration (day), $\mathbf{c}$ number of stopovers, $\mathbf{d}$ stopover duration (day), e travel speed ( $\mathrm{km} /$ day), $\mathbf{f}$ travel duration (day). Also shown are $\mathbf{g}$ mean tailwind assistance experienced in autumn and spring and $\mathbf{h}$ mean autumn and spring daily flying speed in relation to headwind/tailwind. Probability levels for statistically significant differences between autumn and spring migration parameters are shown based on paired $t$-tests and Wilcoxon signed-rank tests, "NS" indicates not significant

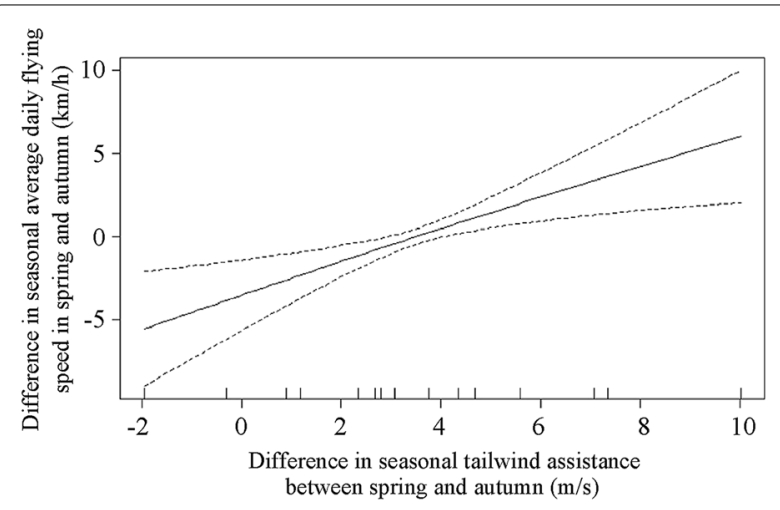

Fig. 4 GAM plot from the best fitting function of the difference in seasonal tailwind $(X$-axis) on the difference in seasonal average daily flying speed ( $Y$-axis). The scale of the $Y$-axis reflects the relative importance of covariate in the model. Dashed lines represent two standard error boundaries around the covariate. Vertical lines along the $X$-axis represent a rugplot of data points used in the analysis to show the distribution of data points over the range of the difference in seasonal tailwinds tailwinds (Allen et al. 1996; Spaar and Bruderer 1996; Meyer et al. 2000), while cross-country speeds of Steppe Eagles (Aquila nipalensis) increased with the increasing tailwind in southern Israel (Spaar and Bruderer 1996). Hence, wind direction and speed have the potential to substantially affect daily travel speed (Vansteelant et al. 2015).

Oriental Storks are c. $40 \%$ heavier than White Storks (Dunning 2007), although structurally and ecologically they are very similar species. Hence, it seems highly likely that the reversal in relative duration of spring and autumn migration in these two species is linked to the degree and strength of tailwinds to which they are exposed during migration along their respective flyway corridors.

Competition for limited reproductive resources has been recognized as a major factor selecting for earliest arrival of territory holders in spring (Kokko 1999). Both Oriental and White Storks occupy traditional nest sites which can be highly limited in the landscape (Luthin 1987), so the incentive to return to defend such nest sites and their associated feeding territories is likely to favour 
the earliest possible return of territory holders in spring, as predicted for such a species (Nilsson et al. 2013). Arrival times at the breeding ground are also negatively correlated with reproductive success in many species, so early avian arrival to breeding grounds ensures benefit from higher territory quality, nesting sites and reproductive success (Møller 1994; Smith and Moore 2005; Gunnarsson et al. 2006; Newton 2008; Janiszewski et al. 2013).

We therefore contend that comparing the duration of spring versus autumn migration in relation to theories about the imperative to arrive first to breeding areas to secure nesting resources is something of a straw man. There is no doubt that both Oriental and White Storks have a similar imperative to arrive as early as possible to occupy and defend valuable nest sites, yet Oriental Storks show no significant difference between autumn and spring migration duration, while White Storks take longer to complete spring migration than covering the same distance in autumn. This study and that of Shamoun-Baranes et al. (2003) show both species are dependent upon tailwind assistance to increase the speed of migration and both studies strongly imply that the seasonal headwind/tailwind ratio in spring versus autumn in Oriental and White Storks contributes to the duration of the migration episode.

We believe that the seasonal differences in the travel speed of Oriental Storks during migration are related to the physical environmental conditions they encounter, which differ in spring compared to autumn. Their faster rate of travel on spring migration can be explained by stronger tailwinds during that season, yet there was no significant difference in the overall duration of autumn and spring migration. The reason might be because the actual travel duration constitutes a relatively small part of overall migration duration, but the stopover duration (which contributes most to migration duration) showed much larger individual variation in spring than autumn. This seems to contrast with the White Storks, which took far longer to complete spring migration than when covering the same distance in autumn, potentially because of more favourable tailwinds in that season compared with headwinds that are encountered in spring (Shamoun-Baranes et al. 2003). This confirms that long distance soaring migrants may strive to shorten the duration of spring migration to ensure earliest arrival at breeding grounds to ensure territorial defence. However, storks are inevitably forced to migrate under the prevailing meteorological conditions in spring, which may differ radically between different flyway populations, dependent on the peculiar local weather patterns to which they are exposed. This finding also confirms the vulnerability of such populations to changes in prevailing atmospheric conditions under current climate change predictions if the prevailing seasonal wind patterns begin to change in the near future, as predicted that they will. Research indicates that changes in wind caused by global warming may have major impacts in the future (McInnes et al. 2011) which could potentially affect migrating storks and other large-bodied avian species.

\section{Conclusions}

We studied the relationship between tailwind and travel speed of the Oriental Stork for the very first time. Although the autumn migration pattern of Oriental Storks has been described previously, our data are the first to show differences between spring and autumn migration travel speed in relation to wind assistance. The results showed that the daily flying speed of Oriental Storks was seasonally affected by differences in the benefit gained from tailwinds throughout the migration episodes, which predictably differed between spring and autumn.

\section{Supplementary information}

Supplementary information accompanies this paper at https://doi. org/10.1186/s40657-020-00196-8.

Additional file 1: Table S1. Summary table of details of 18 first year Oriental Storks (Ciconia boyciana) fitted with solar-powered GPS/GSM telemetry devices attached with backpacks in China 2015-2018 all of which provided full information on spring and autumn migration used in the current analysis. Table S2. Summary table comparing the mean values of autumn and spring migration parameters generated from tagged 18 Oriental Storks (Ciconia boyciana) fitted with solar-powered GPS/GSM telemetry devices in China 2015-2018, which provided full information on spring and autumn migration used in the current analysis. Figure S1. Boxplot showing instantaneous flying speeds of telemetry tracked Oriental Storks presented by each hour of the day, local time. Figure S2. GAM plot from the best fitting function of tailwind at $850 \mathrm{mbar}(X$-axis) on the daily flying speed ( $Y$-axis).

Additional file 2: Supplementary methods.

\section{Acknowledgements}

We thank the staff of the Honghe National Nature Reserve for their invaluable assistance, and especially Bing Li for his help with fieldwork.

\section{Authors' contributions}

SF, HL and QZ performed the experiments, analysed the data, wrote the paper, prepared figures and tables. BZ and SD performed the experiments, did the fieldwork, revised the paper. YX, LC and ADF conceived and designed the experiments, contributed reagents/materials/analysis tools. All authors contributed critically to the drafts. All authors read and approved the final manuscript.

\section{Funding}

The study was supported by the National Key Research and Development Programme of China (Grant No. 2016YFC0500406), International Cooperation and Exchange project NSFC (Grant No. 31661143027), the National Natural Science Foundation of China (Grant Nos. 31870369 and 31970433), and China Biodiversity Observation Networks (Sino BON). 


\section{Availability of data and materials}

The datasets generated during and/or analysed during the current study are not publicly available due to storks in the flyway were highly threatened by illegal hunting, but are available from the corresponding author on reasonable request.

\section{Ethics approval and consent to participate}

We declare that all field methods used in this study were approved by the Forestry Department of Heilongjiang Province under scientific research license (No.23 Hei Forest Protection (2018)). Field research was conducted with permission from the Bureau of the Honghe National Nature Reserve. The Honghe National Nature Reserve shared the tracking data during 2015-2017.

\section{Consent for publication}

Not applicable.

\section{Competing interests}

The authors declare that they have no competing interests.

\begin{abstract}
Author details
${ }^{1}$ School of Life Sciences, University of Science and Technology of China, Hefei 230026, China. ${ }^{2}$ State Key Laboratory of Urban and Regional Ecology, Research Center for Eco-Environmental Sciences, Chinese Academy of Sciences, Beijing 100085, China. ${ }^{3}$ University of Chinese Academy of Sciences, Beijing 100049, China. ${ }^{4}$ Honghe National Nature Reserve, Jiansanjiang 156332, China. ${ }^{5}$ School of Physical Sciences, University of Science and Technology of China, Hefei 230026, China. ${ }^{6}$ Department of Bioscience, Aarhus University, Kalø Grenåvej 14, 8410 Rønde, Denmark.
\end{abstract}

Received: 4 December 2019 Accepted: 14 April 2020

Published online: 23 April 2020

\section{References}

Alerstam T, Hedenstrom A. The development of bird migration theory. J Avian Biol. 1998;29:343.

Allen PE, Goodrich LJ, Bildstein KL. Within- and among-year effects of cold fronts on migrating raptors at hawk mountain, Pennsylvania, 1934-1991. Auk. 1996;113:329-38.

Barter M, Chen L, Cao L, Lei G. Waterbird survey of the middle and lower Yangtze river floodplain in late January and early February 2004. Beijing: China Forestry Publishing House; 2004.

Becciu P, Panuccio M, Catoni C, Dell'Omo G, Sapir N. Contrasting aspects of tailwinds and asymmetrical response to crosswinds in soaring migrants. Behav Ecol Sociobiol. 2018;72:28.

Becciu P, Menz MH, Aurbach A, Cabrera-Cruz SA, Wainwright CE, Scacco M, et al. Environmental effects on flying migrants revealed by radar. Ecography. 2019;42:942-55.

Bengtsson D, Avril A, Gunnarsson G, Elmberg J, Soderquist P, Norevik G, et al. Movements, home-range size and habitat selection of mallards during autumn migration. PLOS ONE. 2014;9:e100764.

Desholm M, Gill R, Bøvith T, Fox AD. Combining spatial modelling and radar to identify and protect avian migratory hot-spots. Curr Zool. 2014;60:680-91.

Dunning JB Jr. CRC handbook of avian body masses. Boca Raton: CRC Press; 2007.

Erni B, Liechti F, Underhill LG, Bruderer B. Wind and rain govern the intensity of nocturnal bird migration in central Europe-a log-linear regression analysis. Ardea. 2002;90:155-66.

Fox AD, Glahder CM, Walsh AJ. Spring migration routes and timing of Greenland white-fronted geese-results from satellite telemetry. Oikos. 2003;103:415-25.

Gunnarsson TG, Gill JA, Atkinson PW, Gélinaud G, Potts PM, Croger RE, et al. Population-scale drivers of individual arrival times in migratory birds: arrival times of migratory birds. J Anim Ecol. 2006;75:1119-27.

Hake M, Kjellén N, Alerstam T. Age-dependent migration strategy in honey buzzards Pernis apivorus tracked by satellite. Oikos. 2003;103:385-96.

IUCN. The IUCN Red List of Threatened Species. Version 2018-2. 2018. http:// www.iucnredlist.org. Downloaded on 26 March 2020.
Janiszewski T, Minias P, Wojciechowski Z. Reproductive consequences of early arrival at breeding grounds in the White Stork Ciconia ciconia. Bird Study. 2013;60:280-4.

Kalnay E, Kanamitsu M, Kistler R, Collins W, Deaven D, Gandin L, et al. The NCEP/NCAR 40-year reanalysis project. Bull Am Meteorol Soc. 1996;77:437-72.

Kemp MU, van Emiel Loon E, Shamoun-Baranes J, Bouten W. RNCEP: global weather and climate data at your fingertips. Methods Ecol Evol. 2012;3:65-70.

Koelzsch A, Mueskens GJDM, Kruckenberg H, Glazov P, Weinzierl R, Nolet BA, et al. Towards a new understanding of migration timing: slower spring than autumn migration in geese reflects different decision rules for stopover use and departure. Oikos. 2016;125:1496-507.

Kokko H. Competition for early arrival in migratory birds. J Anim Ecol. 1999;68:940-50.

Liechti F. Birds: blowin' by the wind? J Ornithol. 2006;147:202-11.

Liechti F, Ehrich D, Bruderer B (1996) Flight behaviour of white storks Ciconia ciconia on their migration over southern Israel. Ardea. 84:3-13

Luthin C. Status of and conservation priorities for the worlds stork species. Colon Waterbirds. 1987;10:181-202.

Mclnnes KL, Erwin TA, Bathols JM. Global climate model projected changes in $10 \mathrm{~m}$ wind speed and direction due to anthropogenic climate change. Atmos Sci Lett. 2011;12:325-33.

Mellone U, Klaassen RHG, García-Ripollés C, Limiñana R, López-López P, Pavón $D$, et al. Interspecific comparison of the performance of soaring migrants in relation to morphology, meteorological conditions and migration strategies. PLOS ONE. 2012;7:e39833.

Mueller T, O'Hara RB, Converse SJ, Urbanek RP, Fagan WF. Social learning of migratory performance. Science. 2013;341:999-1002.

Meyer SK, Spaar R, Bruderer B. To cross the sea or to follow the coast? Flight directions and behaviour of migrating raptors approaching the Mediterranean Sea in autumn. Behaviour. 2000;137:379-99.

Møller AP. Phenotype-dependent arrival time and its consequences in a migratory bird. Behav Ecol Sociobiol. 1994;35:115-22.

Newton NI. The migration ecology of birds. Oxford: Academic Press; 2008.

Nilsson C, Klaassen RHG, Alerstam T. Differences in speed and duration of bird migration between spring and autumn. Am Nat. 2013;181:837-45.

Norberg UM. Vertebrate flight: mechanics, physiology, morphology, ecology and evolution. Berlin Heidelberg: Springer Science \& Business Media; 2012.

Parent O, Ilinca A. Anti-icing and de-icing techniques for wind turbines: critical review. Cold Reg Sci Technol. 2011;65:88-96.

R Development Core Team. R: a language and environment for statistical computing. R Foundation for Statistical Computing. Vienna, Austria; 2017.

Rotics S, Kaatz M, Resheff YS, Turjeman SF, Zurell D, Sapir N, et al. The challenges of the first migration: movement and behaviour of juvenile vs. adult white storks with insights regarding juvenile mortality. J Anim Ecol. 2016:85:938-47.

Rotics S, Kaatz M, Turjeman S, Zurell D, Wikelski M, Sapir N, et al. Early arrival at breeding grounds: causes, costs and a trade-off with overwintering latitude. J Anim Ecol. 2018;87:1627-38.

Rus AI, Duerr AE, Miller TA, Belthoff JR, Katzner TE. Counterintuitive roles of experience and weather on migratory performance. Auk. 2017; 134:485-97.

Safi K, Kranstauber B, Weinzierl R, Griffin L, Rees EC, Cabot D, et al. Flying with the wind: scale dependency of speed and direction measurements in modelling wind support in avian flight. Mov Ecol. 2013;1:4.

Şen Z, Altunkaynak A, Erdik T. Wind velocity vertical extrapolation by extended power law. Adv Meteorol. 2012;2012:178623.

Sergio F, Tanferna A, De Stephanis R, Jiménez LL, Blas J, Tavecchia G, et al. Individual improvements and selective mortality shape lifelong migratory performance. Nature. 2014;515:410-3.

Shamoun-Baranes J, Baharad A, Alpert P, Berthold P, Yom-Tov Y, Dvir Y, et al. The effect of wind, season and latitude on the migration speed of white storks Ciconia ciconia, along the eastern migration route. J Avian Biol. 2003;34:97-104.

Shamoun-Baranes J, Liechti F, Vansteelant WM. Atmospheric conditions create freeways, detours and tailbacks for migrating birds. J Comp Physiol A. 2017;203:509-29. 
Shimazaki H, Tamura M, Darman Y, Andronov V, Parilov MP, Nagendran M, et al. Network analysis of potential migration routes for Oriental White Storks (Ciconia boyciana). Ecol Res. 2004;19:683-98.

Smith RJ, Moore FR. Arrival timing and seasonal reproductive performance in a long-distance migratory landbird. Behav Ecol Sociobiol. 2005;57:231-9.

Spaar R, Bruderer B. Soaring migration of steppe eagles Aquila nipalensis in southern Israel: flight behaviour under various wind and thermal conditions. J Avian Biol. 1996;27:289-301.

Thorup K, Alerstam T, Hake M, Kjellén N. Traveling or stopping of migrating birds in relation to wind: an illustration for the osprey. Behav Ecol. 2006;17:497-502.

Vansteelant WMG, Bouten W, Klaassen RHG, Koks BJ, Schlaich AE, van Diermen $J$, et al. Regional and seasonal flight speeds of soaring migrants and the role of weather conditions at hourly and daily scales. J Avian Biol. 2015;46:25-39.

Vidal-Mateo J, Mellone U, López-López P, La Puente JD, García-Ripollés C, Bermejo A, et al. Wind effects on the migration routes of trans-Saharan soaring raptors: geographical, seasonal, and interspecific variation. Curr Zool. 2016;62:89-97.

Wang Q, Yang Z. Current studies on oriental white stork. J Anhui Univ (Nat Sci). 1995;19:82-99 (in Chinese).

Wang X, Cao L, Bysykatova I, Xu Z, Rozenfeld S, Jeong W, et al. The Far East taiga forest unrecognized inhospitable terrain for migrating Arctic-nesting waterbirds? PeerJ. 2018;6:e4353.
Ready to submit your research? Choose BMC and benefit from:

- fast, convenient online submission

- thorough peer review by experienced researchers in your field

- rapid publication on acceptance

- support for research data, including large and complex data types

- gold Open Access which fosters wider collaboration and increased citations

- maximum visibility for your research: over 100M website views per year

At BMC, research is always in progress.

Learn more biomedcentral.com/submissions 